\title{
Density-dependent parameters and demographic equilibrium in open populations
}

\author{
Giacomo Tavecchia, Roger Pradel, Meritxell Genovart and Daniel Oro \\ G. Tavecchia (g.tavecchia@uib.es), R. Pradel, M. Genovart and D. Oro, IMEDEA (UIB-CSIC), 21 M. Marques, ES-07190 \\ Esporles, Spain.
}

\begin{abstract}
Populations near their equilibrium are expected to show density-dependence through a negative feedback on at least one demographic parameter, e.g. survival and/or productivity. Nevertheless, it is not always clear which vital rate is affected the most, and even less whether this dependence holds in open populations in which immigration and emigration are also important. We assessed the relative importance of population density in the variation of local survival, recruitment, proportion of transients (emigrants) and productivity through the analysis of detailed life-histories of 4286 seabirds from a colony that reached an apparent demographic equilibrium after a period of exponential increase. We provide evidence that the role of population density and resource availability changes according to the demographic parameter considered. Estimates indicated that transients increased from $5 \%$ to $20 \%$ over the study period, suggesting an average turnover of about 1400 individuals per year. The parameters most influenced by population density alone were local survival and probability of transience. Recruitment was negatively associated with population density during the increasing phase but unexpected high values were also recorded at high population levels. These high values were explained by a combination of population size and food availability. Mean productivity varied with food availability, independently from population variations. The population density alone explained up to a third of the yearly variation of the vital rates considered, suggesting that open populations are equally influenced by stochastic and density-independent events (such as environmental perturbations) than by intrinsic (i.e. density-dependent) factors.
\end{abstract}

An important issue in the study of population dynamics is the role and the mechanisms through which population size bounds population growth rate (Cappuccino and Price 1995, Berryman et al. 2002, reviewed by Murdoch 1994, Turchin 1995, Newton 1998, Sibly and Hone 2002). As populations approach their maximum size, comparative studies have shown evidence of a negative feedback of the population size in early survival, recruitment, reproductive rate, and adult survival (Sinclair 1996, Gaillard et al. 1998, Eberhardt 2002), sometimes in such specific sequence (Eberhardt 1977, Fowler 1987). This evidence, however, concerns mainly populations of mammals and more importantly, they focused on relatively closed populations without any reference to spatial parameters. Indeed, the majority of theoretical and empirical studies on the determinants of population growth rate in wildlife populations with overlapping generations have no explicit spatial factors, i.e. do not consider emigration and immigration, and the mathematical link between successive values of population size made by the Euler-Lotka equation only consider local vital rates (Pfister 1998). In marine systems, for example, Hixon et al. (2002), have recently outlined the importance of the spatial scale at which regulation processes are studied and how local population models tend to neglect the role of immigration and emigration on local dynamics (Cam et al. 2004). It is still unclear thus how parameters such as dispersal or immigration are affected by population density in open systems where movements of individuals are demographically significant (Pulliam 1988, Clobert et al. 2001, Hanski and Gaggiotti 2004). Eberhardt's paradigm of an initial increase in early mortality and age of first breeding in 
populations approaching their carrying capacity might not hold for open populations. For example, if new recruits come mainly from other populations, i.e. immigrants, a change in early local survival will not necessarily translate into population variation. Also, a recent review has provided evidence of a positive density-dependent dispersal in both, birds and mammals (Matthysen 2005). Despite the need for more empirical studies (Turchin 1995, Hixon et al. 2002, Weimerskirch 2002), the relative roles of densitydependent factors on individual processes have seldom been quantified in open populations. This is due to the difficulty of collecting detailed data on enough individuals to achieve acceptable precision in population parameters and for a period long enough to 'witness' a change in the growing regime. It also explains why determinants of population growth rate have classically been derived by the analyses of observed population size, even though is always more valuable to analyze this relationship through the effects of population density on demographic parameters (Lebreton and Clobert 1991, Coulson et al. 2001). Here we investigate how demographic parameters, included those typical of open systems, influence the dynamic of a colony of Audouin's gull Larus audouinii from a phase of population increase to an apparent stabilization in numbers using detailed long-term information on marked birds. Throughout the manuscript we use the term 'equilibrium' to refer to this apparent constant value to which the population seems to come back if disturbed (Turchin 2001) and the term 'demographic' to specify that this relates to population size and not to population age-structure or genetic composition. We are interested in measuring the role of population size in explaining the variability of the parameters. There is a general consensus that the high growth rate observed during the increasing phase is seldom self-sustained (Newton 1998) and it could not be achieved without immigration (Harris and Wanless 1991, Oro and Ruxton 2001). Previous work showed that the growth rate of Audouin's gull colonies is strongly influenced by dispersal of individuals with a higher level of exchange between neighboring colonies (Oro 1999, Oro et al. 1999, 2004b, Cam et al. 2004). At the local level, the dynamic of the studied colony showed two distinctive phases: (1) a phase of exponential growth, with an average annual rate of $43 \%$, (2) a phase (approx. after 1995) of apparent dynamic equilibrium, during which the population fluctuated around an average value of about 10000 breeding pairs.

\section{Hypotheses and covariates}

We aim to 1) verify whether population growth rate was influenced by population density, and 2) quantify the role of density-dependent and density-independent (i.e. environmental) factors in explaining the temporal variation of demographic parameters, including those typical of open systems. We estimated four parameters underlying colony dynamics: the adult survival probability, the recruitment probability (i.e. the probability of being a new breeder), the probability of transience (i.e. the probability of leaving the colony after the first breeding attempt), and the colony productivity (i.e. the average number of fledglings per breeding pair). Assuming that the observed change in the growing regime was due to a change in one or more of these parameters (Hixon and Carr 1997), we consider four external covariates and one factor as predictors of these changes (below). First we consider the total number of Audouin's gulls breeding in the colony. If the population negative feedback is the main cause of the change in growth regime, we expect it to explain a significant part of the variation in at least one of these parameters. The second covariate investigated is a measure of annual food availability: since the main resource exploited by gulls in the Ebro Delta colony is fishing discards ( $75 \%$ by biomass) we take the catch statistics at the local fishing harbours as a proxy of this measure (Oro 1999). Moreover, if the mechanistic explanation is a reduction in the per-capita intake of resources then the ratio of the fish catches (below) to the total number of individuals sharing the same resource (i.e. a measure of intra-guild competition) would be a better predictor. As third covariate we consider the ratio of fish catches to the total number of breeding pairs of Audouin's gulls and of the sympatric yellow-legged gulls, L. michahellis (Oro et al. 2006). The two species compete for similar resources as shown by the high degree of overlap in the diet and breeding habitat (Martínez-Abraín et al. 2003, Oro et al. 2006). The fourth covariate consider was the North Atlantic oscillation index (NAO hereafter, Hurrell 1995) taken as a measure of winter conditions. The NAO is a global measure of winter conditions at Northern latitudes correlated with many biological processes through its influence on local climate (Stenseth and Lima 2002). Although its effects on biological systems in the Mediterranean region have rarely been investigated, the NAO is highly correlated with local climate in south-western Spain and with the run-off of the major rivers, included the Ebro river (Rodo et al. 1997, Lloret et al. 2001). Finally, we consider the effect of a terrestrial predator, a fox (Vulpes vulpes), that entered the colony in 1999 causing a strong environmental perturbation through high mortality among breeders. These five external variables shall be used as predictors of demographic parameters and their importance calculated as the proportion of temporal variability explained. 


\section{Methods}

\section{Estimating population size}

The annual censuses of nests with at least one egg were used as estimates of population density; the method performed was the same over the years and it yielded small count errors (Oro and Ruxton 2001). Several plots were explored to qualitatively test the density paradigm: a) the change in breeding pair numbers $(\mathrm{N})$ since the colonization of the study colony in $1981 ; \mathrm{b}$ ) a Ricker diagram showing changes in $\mathrm{N}_{\mathrm{t}+1}$ with respect to values of $\mathrm{N}_{t}$; and c) the relationship between population growth rate $\left(r\right.$, expressed as the $\log _{e}$ of the equation $\mathrm{N}_{\mathrm{t}+1} / \mathrm{N}_{\mathrm{t}}$, also known as finite rate of increase or $\lambda$ ) and population density.

\section{The capture-recapture framework}

From 1988 to 2003 gulls were individually marked at fledging using a darvic band with a unique alphanumeric code. Gulls were resighted at the colony during 1992-2003, and their breeding status was recorded when possible. Estimates of survival (noted $\phi$ hereafter) and recruitment, noted $\beta$ (i.e. the complement of the seniority probability, $\gamma$, Pradel et al. 1997b) were obtained through the analysis of observations of marked animals of known age retaining only those made on sexually mature gulls ( $\geq 3$ years old, 4286 individuals in total, Williams et al. 2002). Recruitment measures can be obtained from capture-recapture data using different approaches (Pradel and Lebreton 1999, Schwarz and Arnason 2000). These measures are not equivalent and as consequence not directly comparable. The measure $\beta$ considered here is cohort-based and should be viewed as the probability that a bird of a particular cohort, i.e. age, seen for the first time at a given occasion has just recruited. We chose this measure to be able to compare results with a previous study of the same population (Oro and Pradel 1999). In addition to $\phi$ and $\beta$, we estimated the proportion of transient, $\tau$. Pradel et al. (1997b) showed that the initial survival probability, noted $\phi^{\prime}$ hereafter, incorporates the proportion of transients at time $i, \tau_{i}$, as $\phi_{\mathrm{i}}^{\prime}=\left(1-\tau_{\mathrm{i}}\right) \phi_{\mathrm{i}}$ (Oro et al. 1999, Perret et al. 2003). The program MARK4.1 (White and Burnham 1999) was used to derive survival, recruitment and recapture probabilities.

\section{Testing the adequacy of capture-recapture hypotheses}

Assumptions of capture-recapture modelling can be tested by a $\chi^{2}$ test goodness-of-fit test (Pollock et al. 1990). Different components of the global $\chi^{2}$ test, namely test3.SR, test3.CT, test2.SM and test2.CT can help to identify the source of heterogeneity (Choquet et al. 2000). When the source of heterogeneity can not be identified or it would be unrealistic to further complicate model structure, a variance inflator factor, $\hat{c}$, is used to scale model deviances (Lebreton et al. 1992, Tavecchia et al. 2001). The value of $\hat{c}$ is calculated as the ratio of the global goodness-of-fit $\chi^{2}$ value to its degrees of freedom. In our case, the survival and recruitment analyses were based on the same data. Hence the goodness-of-fit and the corresponding $\hat{c}$ were unique. The goodness-of-fit test was calculated using program U_CARE2.2 (Choquet et al. 2000), which includes directional tests (Z-tests) on contingency tables that are specifically designed to detect systematic departures from model assumptions, e.g. whether significantly large $\chi^{2}$ values were due to the presence of transients.

\section{Testing the influence of time, age and covariates}

Our capture-recapture models involved five types of parameters: the survival probability of newly seen birds $\left(\phi^{\prime}\right)$, the survival probability of resident birds $(\phi)$, the seniority probabilities $\left(\gamma\right.$ and $\left.\gamma^{\prime}\right)$, and the detection probability $(\mathrm{p})$. The factors considered as predictors of these parameters were time (12 levels, noted ' $t$ ' in model notation) and age (12 levels from 3 - the age at first breeding-to 14 , noted a or $A_{j}$ if used as a covariate to $\mathrm{j}$-age). In addition we considered five external variables as predictors of the time dependent variation (Introduction): the total number of breeding pairs of Audouin's gull at the Ebro delta colony (noted G), the total amount of fish catch statistics (noted F), the percapita resource intake, i.e. the fish catches divided by total number of breeding Audouin's and yellow-legged gulls considered together, (noted L), the North Atlantic oscillation index, (noted, N) and the effect of a fox in 1999 (noted v). Note that this last factorial variable considers two periods, one with the presence of a predator (1998-2000, since mortality occurred simultaneously with observations) and one without (from 1992 to 1998 and from 2000 to 2003). In general terms, we were interested in decomposing the timedependent variation around the average value of the parameter, $\theta$, estimating how much of this variation was explained by the covariate $\mathrm{X}$. We proceeded as follows: if $\Delta$ is the difference in deviance between the model assuming full time dependence and the one assuming constant $\theta$, namely deviance $\theta()-.\operatorname{deviance} \theta(\mathrm{t})$, the percentage of total variation explained by $\mathrm{X}$ is $($ deviance $\theta()-$. deviance $\theta(\mathrm{X})) / \Delta$. The procedure ANODEV in MARK4.1 tests whether the explained variance was statistically significant (Harris et al. 2005). We used one-tailed tests when testing the effect of population 
density as a negative influence was expected. Finally, in model notation ' $x$ ' denoted the interacting effects, while if the main effects were considered alone a ' + ' was used instead. To select the most appropriate model we progressively eliminated effects on each parameter separately and kept the structure of the others as general as possible (Grosbois and Tavecchia 2003, Tavecchia et al. 2005). Model selection followed the Akaike's information criterion (QAIC; Burnham and Anderson 2002).

\section{Average productivity}

The productivity of the colony was measured as the average number of chicks fledged per breeding pair (Oro et al. 1999). The two variables were derived independently. The total number of chicks was estimated by a two-session capture-recapture method (Williams et al. 2002). The number of breeding pairs was taken from the annual census of nests with at least one egg. Values were analyzed using generalized linear models (Crawley 1993). As for survival and recruitment probabilities we estimated the amount of temporal variation explained by each covariate, tested separately. Given the relatively short time-series in productivity we avoid models including multiple predictors.

\section{Results}

\section{Population size}

Censuses indicated that the Audouin's gull population at the Ebro delta increased exponentially since its colonization in 1981 to 1997 and subsequently fluctuated about a mean of 10000 pairs (Fig. 1A-B). A plot of the influence of population density on population growth rate, $r$ (Fig. 1C) showed a strong association between the two variables (logarithmic regression fit $\left.\mathrm{R}^{2}=0.733, \mathrm{~F}_{22}=21.84, \mathrm{p}<0.0001\right)$. Despite an average recapture probability of about 0.70 (Oro et al. 1999), 33\% of the 4286 individuals analyzed were seen only once over the entire study period. Among these 'transient' animals, the proportion of known breeders was similar to the one found for resident birds ( $4.4 \%$ and $3.8 \%$ respectively).

\section{Testing the adequacy of capture-recapture hypotheses}

The goodness-of-fit test of the model including age, time and their interactions (Model 1, hereafter) indicated that a significantly large part of the deviance remained unexplained $\left(\chi_{257}^{2}=1037.24, \mathrm{p}<0.001\right)$. As expected, the specific components of the goodness of fit and
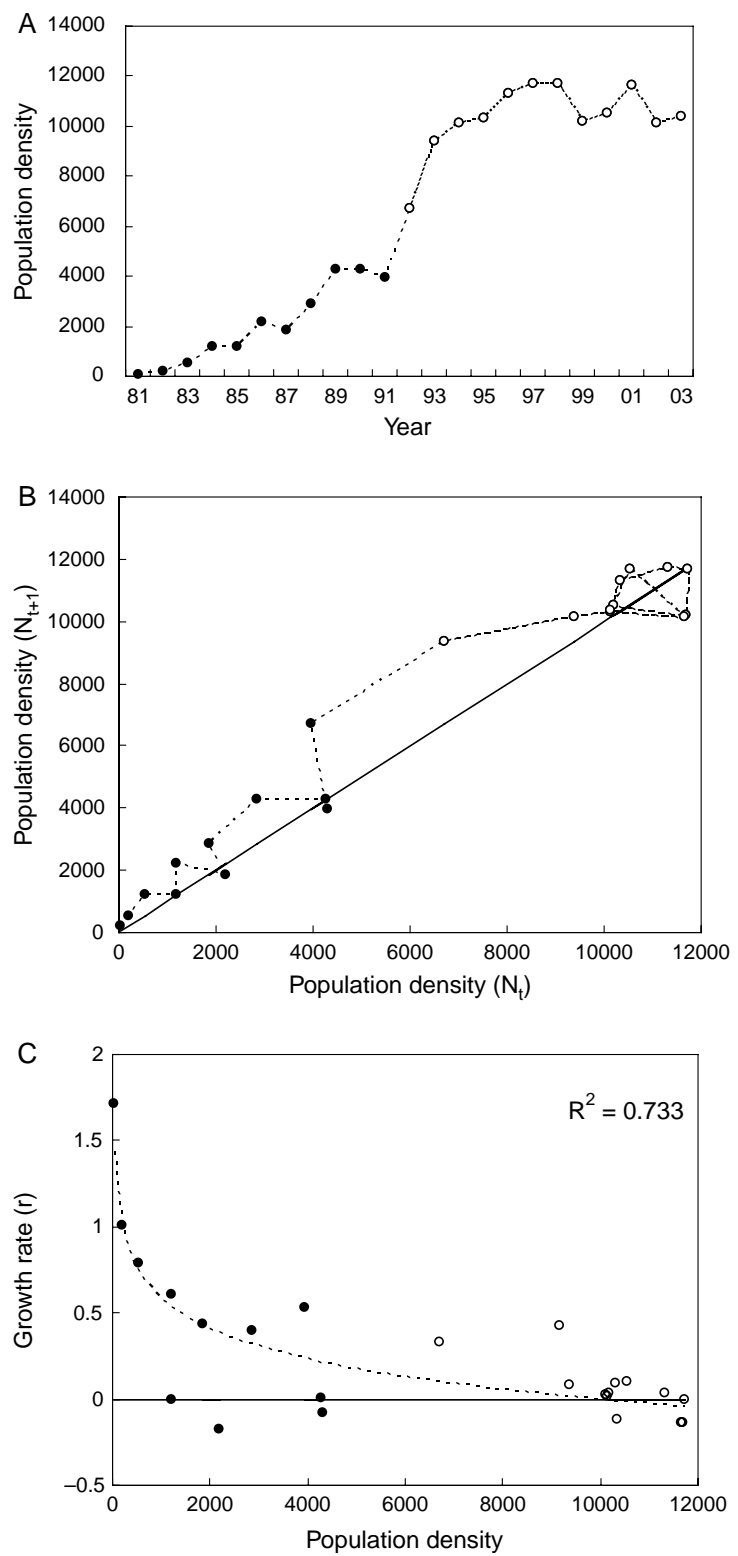

Fig. 1. (A) Changes in population density (N) of the study colony since the colonization in 1981; the white symbols indicate the period during which detailed individual information on breeders was collected; (B) Ricker diagram of the population values; the straight line shows the equilibrium value when $N_{t}=N_{t+1}$; and (C) the $r$-function, i.e. the changes in population growth rate $\mathrm{r}$ with density during 1981-2003 and the statistical value of the logarithmic correlation coefficient; here the straight line shows the $r$ value when population was stable $(\mathrm{r}=0)$.

the directional Z-test pointed out a strong transient effect (test3SR: $\chi_{64}^{2}=687.43, p<0.001 ; Z=22.44$, $\mathrm{p}<0.001)$. This lack of fit was corrected including extra parameters for newly observed birds. Yet, there was 
evidence of a large residual deviance $\left(\chi_{193}^{2}=349.81\right.$, $\mathrm{p}<0.001$ ), in part due to the trap-dependence of a subset of gulls that was systematically observed more than others $(Z=-9.58 ; \mathrm{p}<0.001)$. In order to avoid complicating the analysis by increasing model parameters, we scaled model deviance (Discussion) using a variance inflator factor $(\hat{\mathrm{c}}=349.81 / 193=1.813)$.

\section{Survival, transience and recapture probabilities}

Time had a significant effect on all parameters whilst age negatively influenced $\phi^{\prime}$ but had no effect on $\phi$ (Table 1). A further reduction in QAICc value was obtained by modeling age as a continuous function (Model 3, hereafter). The negative slope of the age predictor indicated that transience probability, increased with the age of the bird (Fig. 2A). We successfully reduced the QAICc value by assuming a similar effect of time on $\phi^{\prime}$ and $\phi$, i.e. parallel regression (Model 4). The proportion of transients, $\tau_{1}$ (calculated as $1-\left(\phi_{\mathrm{i}}^{\prime} / \phi_{\mathrm{i}}\right)$ ), was constant on a logit scale, but in the transformed scale increased from 5.0\% to $19.5 \%$. A model with a trend in survival (Model 6) provided the lowest QAICc values so far (Table 1, Fig. 2B). When testing for a trend and the influence of the external covariates, we excluded the last estimates (year 2002), as survival was exceptionally low (Fig. 2B) and in the presence of trap-dependence, the last values can be negatively biased. We empirically tested the possible bias by building a series of datasets in which we systematically removed the last-year observations (results not shown). The bias was concentrated on the last parameter only; for example, by removing last-year observations (year 2003) the survival parameter of the year before changed by $2 \%$, but only by $4 \%$ and $2 \%$ in the previous two years. This evidence suggested that with the exception of the last parameter the biases induced by the recapture heterogeneity were negligible. The amount of time-dependent variation around the average value of $\phi^{\prime}$ and $\phi$ was the difference in deviance between Model 4 and $5(\Delta \mathrm{Dev}=101.42)$. We measured how much of this variation was explained by the four covariates when tested alone (the fox event was not considered as it was treated as a factor). We first checked the between-covariates association using the Pearson's correlation coefficient, $r_{c}$. As expected, we found a strong association between $F$ and $\mathrm{L}\left(\mathrm{r}_{\mathrm{c}}=0.90, \mathrm{p}<0.001\right)$ as these variables were not independent. Correlation between $G$ and $F$ and between $G$ and $L$, were not significant $\left(r_{c}=0.09\right.$, $\mathrm{p}>0.05$ and $\mathrm{r}_{\mathrm{c}}=-0.278, \mathrm{p}>0.05$, respectively) even

Table 1. Modeling survival ( $\phi^{\prime}$ and $\phi$, for transient and resident gulls respectively), and recapture $(p)$ probabilities. QDev $=$ model deviance, $\mathrm{np}=$ number of model parameters, $\triangle \mathrm{QAICc}=$ difference from the lowest QAICc value. $\mathrm{Aj}=$ age as continuous variable up to age $\mathrm{j}(3<\mathrm{j}<15)$. The symbol // indicates parallel regression (the effect is assumed to have the same influence on $\phi$ and $\left.\phi^{\prime}\right)$. Retained model is in bold.

\begin{tabular}{|c|c|c|c|c|c|c|}
\hline Model & $\phi^{\prime}$ & $\phi$ & $\mathrm{p}$ & QDEV & $\mathrm{np}$ & $\triangle \mathrm{QAICc}$ \\
\hline \multicolumn{7}{|c|}{ Age and time-dependent models } \\
\hline \multirow[t]{4}{*}{ Model 1} & $a \times t$ & $a \times t$ & $\mathrm{a} \times \mathrm{t}$ & 2688.28 & 304 & 364.79 \\
\hline & $a \times t$ & $a \times t$ & . & 3158.05 & 154 & 522.72 \\
\hline & $\mathrm{a} \times \mathrm{t}$ & $\mathrm{t}$ & $\mathrm{a} \times \mathrm{t}$ & 2724.50 & 237 & 260.73 \\
\hline & $\mathrm{a} \times \mathrm{t}$ & $a \times t$ & $\mathrm{t}$ & 2778.64 & 163 & 161.79 \\
\hline Model 2 & $a+t$ & $\mathrm{t}$ & $\mathrm{t}$ & 2895.02 & 41 & 29.94 \\
\hline \multirow[t]{2}{*}{ Model 3} & $\mathrm{~A}_{15}+\mathrm{t}$ & $t$ & $\mathrm{t}$ & 2900.32 & 33 & 19.14 \\
\hline & $\mathrm{t}$ & $\mathrm{t}$ & $\mathrm{t}$ & 3014.55 & 32 & 131.36 \\
\hline Model 4 & $\mathrm{~A}_{15}+\mathrm{t} / /$ & $\mathrm{t} / /$ & $\mathrm{t}$ & 2902.79 & 24 & 3.52 \\
\hline Model 5 & $\mathrm{~A}_{15}$ & . & $\mathrm{t}$ & 3004.21 & 16 & 88.89 \\
\hline Model 6 & $\mathbf{A}_{15}+\mathrm{T} / /$ & $\mathrm{T} / /$ & $\mathbf{t}$ & 2913.76 & 17 & 0.44 \\
\hline \multicolumn{7}{|c|}{ Models including single covariates } \\
\hline \multirow[t]{5}{*}{ Model 7} & $\mathrm{~A}_{15}+\mathrm{G} / /$ & $\mathrm{G} / /$ & $\mathrm{t}$ & 2969.54 & 17 & 56.22 \\
\hline & $\mathrm{A}_{15}+\mathrm{F} / /$ & $\mathrm{F} / /$ & $\mathrm{t}$ & 3003.66 & 17 & 90.34 \\
\hline & $\mathrm{A}_{15}+\mathrm{L} / /$ & $\mathrm{L} / /$ & $\mathrm{t}$ & 3001.89 & 17 & 88.57 \\
\hline & $\mathrm{A}_{15}+\mathrm{N} / /$ & $\mathrm{N} / /$ & $\mathrm{t}$ & 3001.05 & 17 & 87.29 \\
\hline & $A_{15}+v / /$ & $\mathrm{v} / /$ & $\mathrm{t}$ & 2981.09 & 17 & 67.77 \\
\hline \multicolumn{7}{|c|}{ Models including multiple covariates } \\
\hline & $\mathrm{A}_{15}+\mathrm{T}+\mathrm{v} / /$ & $\mathrm{T}+\mathrm{v} / /$ & $\mathrm{t}$ & 2911.31 & 18 & 0 \\
\hline & $\mathrm{A}_{15}+\mathrm{T}+\mathrm{F} / /$ & $\mathrm{T}+\mathrm{F} / /$ & $\mathrm{t}$ & 2911.45 & 18 & 0.14 \\
\hline & $\mathrm{A}_{15}+\mathrm{T}+\mathrm{L} / /$ & $\mathrm{T}+\mathrm{L} / /$ & $\mathrm{t}$ & 2912.23 & 18 & 0.92 \\
\hline & $\mathrm{A}_{15}+\mathrm{T}+\mathrm{G} / /$ & $\mathrm{T}+\mathrm{G} / /$ & $\mathrm{t}$ & 2912.68 & 18 & 1.37 \\
\hline & $\mathrm{A}_{15}+\mathrm{G}+\mathrm{v} / /$ & $G+v / /$ & $\mathrm{t}$ & 2956.91 & 18 & 45.6 \\
\hline & $\mathrm{A}_{15}+\mathrm{G}+\mathrm{F} / /$ & $G+F / /$ & $\mathrm{t}$ & 2965.07 & 18 & 53.76 \\
\hline & $\mathrm{A}_{15}+\mathrm{F}+\mathrm{v} / /$ & $F+v / /$ & $\mathrm{t}$ & 2970.85 & 18 & 59.54 \\
\hline & $\mathrm{A}_{15}+\mathrm{F}+\mathrm{G}+\mathrm{F} . \mathrm{G} / /$ & $\mathrm{F}+\mathrm{G}+\mathrm{F} . \mathrm{G} / /$ & $\mathrm{t}$ & 2956.34 & 19 & 47.04 \\
\hline & $\mathrm{A}_{15}+\mathrm{N}+\mathrm{G}+\mathrm{N} \cdot \mathrm{G} / /$ & $\mathrm{N}+\mathrm{G}+\mathrm{N} \cdot \mathrm{G} / /$ & $t$ & 2963.35 & 19 & 53.60 \\
\hline
\end{tabular}



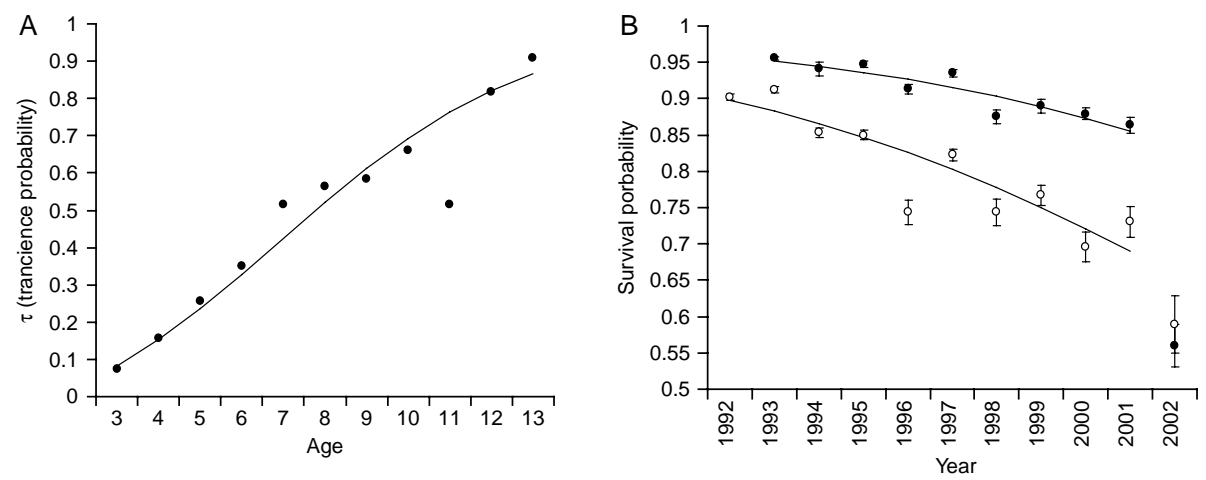

Fig. 2. (A) Transience probability, $\tau\left(1-\phi^{\prime} / \phi\right)$, according to age at first resighting (values from year 2001); black dots: full-age effect (Model 2); line: model assuming a linear effect of age on a logit scale (Model 3). (B) Time-dependent variation of survival parameters according to Model 3 (note that the Y-axis starts at 0.5); black symbols: resident birds, white symbols: 'first-year' survival (only values for age 4 were plotted). The black lines were from Model 6 assuming a linear trend for both survivals from 1992 to 2001. Bars indicated 95\% confidence intervals.

if the latter were not independent. We did not, however, expect to find a negative significant association between $\mathrm{NAO}$ values and fish catches $\left(\mathrm{r}_{\mathrm{c}}=-\right.$ $0.71, \mathrm{p}<0.01$ ). This was due to the unusually high fish catch in 1994 when NAO was at its lowest level: after excluding 1994 the correlation was still negative but not significant $\left(r_{c}=-0.47, p=0.17\right)$. To avoid problems of collinearity the variables $\mathrm{NAO}, \mathrm{F}$ and $\mathrm{L}$ were never included in the same model. All covariates had a negative effect on local survival, but none of the density-independent variables alone explained a significant part of the variation around the average value (Table 2). In contrast the population density of Audouin's gull when tested alone was significant $(p=0.05)$ and explained 34\% of the yearly variation in local survival. Note that although this covariate explained a significant part of that variation, the model was not retained (Table 1, Fig. 2B) because the explained variance was small compared to the total variance. Finally, the predation event increased mortality between 1997 and 1998 of 6\% (2\% if the trend was taken into account) but the effect of the predatorperturbation seemed to last longer than the interval considered. From 1992 to 1997 survival probability was 0.933 (95\% confidence interval: $0.929-0.938$ ) and it decreased to $0.878(0.853-0.899)$ afterwards (Fig. 2B). Models including multiple variables did not substantially improve the QAICc value with the exception of those containing the temporal trend. Note that the population size explained only $1 \%$ of the temporal variance around the trend however their values before 1997 are strongly associated as population increased constantly. Model 6 however was still preferred due to its lower number of parameter. Recapture probability did not vary as a function of age and generally increased over the study period: its average value was 0.680 (95\% confidence limits: $0.667-0.692)$.

\section{Recruitment probability}

Model selection began from the general model $\gamma_{t^{*} a}^{\prime} \gamma_{t^{* a}}$ $\mathrm{p}_{\mathrm{t}}$. This model was the equivalent of Model 1 with the exception that detection probability now varied only over time. Note that $\gamma s$ referred to transient animals $\left(\gamma^{\prime}\right)$ have not a clear biological interpretation (Oro et al. 1999) but should be included in the models as suggested by the goodness-of-fit test to obtained unbiased estimate of the parameters of interest. For this reason their values will not be considered further. The lower QAICc value of Model 12 suggested that individuals recruited between ages 3 and 6 (Table 2, Fig. 3A). In contrast with the analysis of survival, a linear effect of age on $\gamma^{\prime}$ was not retained. Because $\gamma$ for age 3 was 0 (i.e. all gulls breeding at 3 years old were new breeders), the temporal variability in the recruitment probability (Fig. 3B) was confined to three ages only (ages 4, 5 and 6). When tested alone, none of the external variables considered improved the QAICc. In particular, the total number of breeding Audouin's gulls, G, explained $32 \%$ of the temporal variation $(\mathrm{p}=0.03)$ but the model was not retained (Table 2). However when the two years when high probability of recruitment occurred at high population density were singled out (years 1998 and 2001; Fig. 3B) this value increased to $70 \%(\mathrm{p}=0.001)$. A model including population size $(\mathrm{G})$, the food availability, $(\mathrm{F})$ and their interaction explained most of the temporal variability $(77 \%)$ in recruitment probability (Model 18 ; Table 3 ). This was also true when the per-capita intake of resource was considered (L: Model 19; Table 3). 
Table 2. Effect of covariates on survival $(\phi)$, recruitment $(\gamma)$ and productivity expressed as the percentage of variance explained (see text). Note that transience and age at first breeding probabilities varied in parallel with non-transient (i.e. resident) survival and seniority (i.e. recruitment) probabilities. $\Delta \mathrm{Dev}=$ total variance; $\mathrm{CV}=\mathrm{coefficient}$ of variation. $\mathrm{G}=\mathrm{local}$ population size of Audouin's gull at time $\mathrm{i} ; \mathrm{L}=$ population size of Audouin's and yellow legoed-gulls at time $\mathrm{i}$; $\mathrm{F}=$ total fish catches declared at a local harbour in year $\mathrm{i}$. NAO $=$ North Atlantic oscillation index; $T=$ trend; $v=$ parameters for 1998 and 1999 was considered separately (predator effect). $-=$ not tested due to the small sample size. $\dagger=$ one-tailed tests. Significant percentages are marked in bold. When tested alone, the direction of the effect is in brackets. Note that variables $\mathrm{L}$ and $\mathrm{F}$ were not independent and were never used simultaneously.

\begin{tabular}{|c|c|c|c|c|c|c|c|c|c|c|c|}
\hline & $\Delta \mathrm{Dev}$ & $\mathrm{CV}$ & G & L & $\mathrm{F}$ & $\mathrm{N}$ & $\mathrm{T}$ & $G+F$ & $\mathrm{G}+\mathrm{T}$ & $\mathrm{G}+\mathrm{N}+\mathrm{G} . \mathrm{N}$ & $G+F+G . F$ \\
\hline Survival $(\phi)$ & 101.01 & 0.13 & $\begin{array}{l}34 \%(-) \\
p=0.05 \dagger\end{array}$ & $\begin{array}{l}2 \% \\
p=0.35 \dagger\end{array}$ & $\begin{array}{l}1 \%(-) \\
p=0.78\end{array}$ & $\begin{array}{l}3 \%(-) \\
p=0.65\end{array}$ & $\begin{array}{l}89 \%(-) \\
p=0.00 \dagger\end{array}$ & $\begin{array}{l}38 \% \\
p=0.23\end{array}$ & $\begin{array}{l}\mathbf{9 0} \% \\
\mathbf{p}=\mathbf{0 . 0 0}\end{array}$ & $\begin{array}{l}40 \% \\
p=0.42\end{array}$ & $\begin{array}{l}47 \% \\
p=0.32\end{array}$ \\
\hline Recruitment $(\gamma)$ & 59.70 & 0.84 & $\begin{array}{l}32 \%(-) \\
p=0.04 \dagger t\end{array}$ & $\begin{array}{l}11 \% \\
p=0.19 \dagger\end{array}$ & $\begin{array}{l}22 \%(-) \\
p=0.14\end{array}$ & $\begin{array}{l}0.1 \%(-) \\
p=0.99\end{array}$ & $\begin{array}{l}7 \%(+) \\
p=0.22 \dagger\end{array}$ & $\begin{array}{l}65 \% \\
p=0.01\end{array}$ & $\begin{array}{l}42 \% \\
p=0.25\end{array}$ & $\begin{array}{l}34 \% \\
p=0.37\end{array}$ & $\begin{array}{l}77 \% \\
p=0.01\end{array}$ \\
\hline Productivity & 4.22 & 0.48 & $\begin{array}{l}5 \%(-) \\
p=0.26 \dagger\end{array}$ & $\begin{array}{l}46 \%(+) \\
p=0.02 \dagger\end{array}$ & $\begin{array}{l}57 \%(+) \\
p=0.001 \dagger\end{array}$ & $\begin{array}{c}11 \%(-) \\
p=0.31\end{array}$ & $\begin{array}{l}17 \% \\
p=0.101 \dagger\end{array}$ & - & - & - & - \\
\hline
\end{tabular}

The value increased to $70 \%(p=0.001)$ when years 1998 and 2001 were excluded (Fig. 3B).
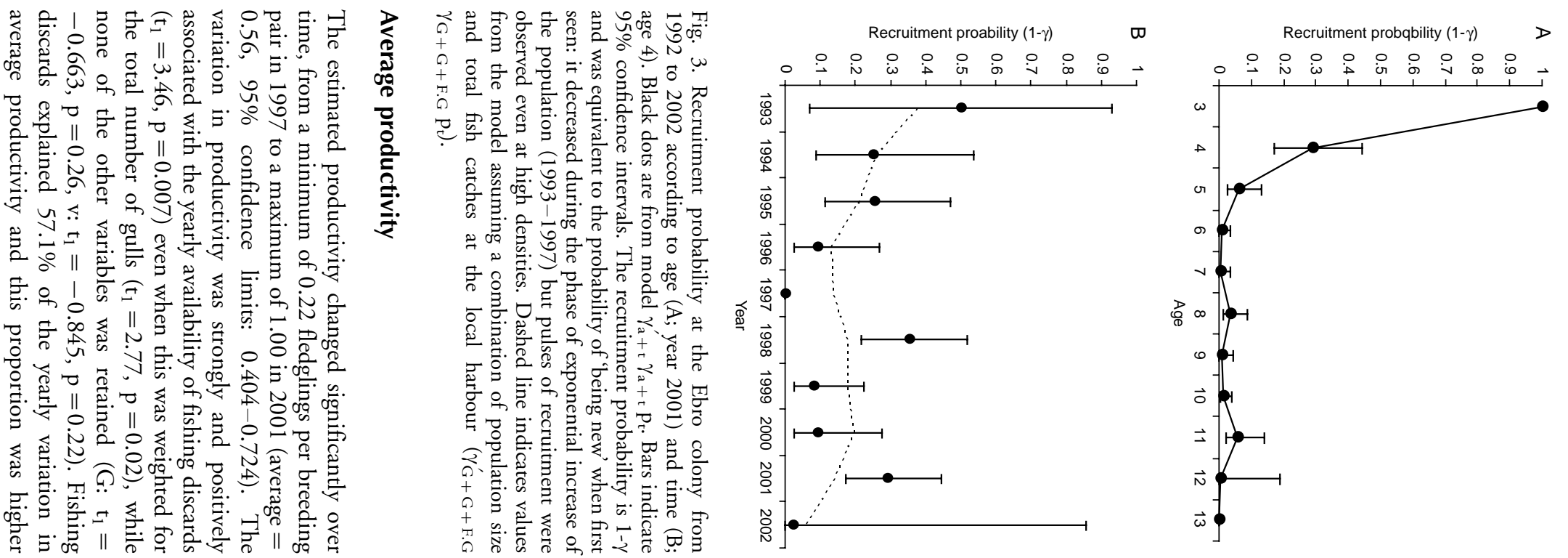
Table 3. Modelling seniority (i.e. recruitment) probability $\left(\gamma^{\prime}\right.$ and $\gamma$ ). The structure in the recapture probability has been kept as in Model 8 (Table 1). QDev = model corrected deviance, $\mathrm{np}=$ number of model parameters, $\Delta$ QAICc $=$ difference from the lowest QAICc value. Note that in models 15, 17 and ultrastructural models effects are assumed to have the same influence on $\gamma$ and $\gamma^{\prime}$ (parallel regression, noted //). Retained model is in bold.

\begin{tabular}{|c|c|c|c|c|c|}
\hline Model & $\gamma^{\prime}$ & $\gamma$ & QDEV & $\mathrm{np}$ & QAICC \\
\hline \multicolumn{6}{|c|}{ Age and time-dependent models } \\
\hline Model 8 & $\mathrm{a} \times \mathrm{t}$ & $a \times t$ & 2819.14 & 153 & 137.11 \\
\hline Model 9 & $\mathrm{a}+\mathrm{t}$ & $a \times t$ & 2873.53 & 89 & 61.16 \\
\hline \multirow[t]{3}{*}{ Model 10} & $\mathrm{a}+\mathrm{t}$ & $\mathrm{a}+\mathrm{t}$ & 2901.40 & 55 & 20.29 \\
\hline & $\mathrm{a}+\mathrm{t}$ & $\mathrm{a}_{10}+\mathrm{t}$ & 2907.40 & 51 & 18.23 \\
\hline & $\mathrm{a}+\mathrm{t}$ & $\mathrm{a}_{9}+\mathrm{t}$ & 2909.65 & 49 & 16.45 \\
\hline Model 11 & $\mathrm{a}+\mathrm{t}$ & $a_{7}+t$ & 2910.32 & 47 & 13.09 \\
\hline Model 12 & $\mathrm{a}+\mathrm{t}$ & $a_{6}+t$ & 2911.99 & 46 & 12.74 \\
\hline Model 13 & $\mathrm{a}+\mathrm{t}$ & $\mathrm{a}_{6}$ & 2934.25 & 36 & 14.88 \\
\hline Model 14 & $\mathrm{a}+\mathrm{t}$ & $a_{5}+t$ & 2955.98 & 45 & 54.72 \\
\hline Model 15 & $a+t$ & $\mathrm{a}_{4}+\mathrm{t}$ & 2961.72 & 44 & 58.45 \\
\hline \multirow{2}{*}{ Model 16} & $a+t / /$ & $a_{6}+t / /$ & 2919.94 & 36 & 0.57 \\
\hline & $\mathrm{a} / /$ & $\mathrm{a}_{6} / /$ & 2979.64 & 26 & 40.17 \\
\hline \multicolumn{6}{|c|}{ Models including single covariates } \\
\hline \multirow[t]{6}{*}{ Model 17} & $\mathrm{a}+\mathrm{T} / /$ & $\mathrm{a}_{6}+\mathrm{T} / /$ & 2975.71 & 27 & 38.25 \\
\hline & $a+G / /$ & $\mathrm{a}_{6}+\mathrm{G} / /$ & 2960.34 & 27 & 22.88 \\
\hline & $a+F / /$ & $a_{6}+F / /$ & 2966.45 & 27 & 28.99 \\
\hline & $\mathrm{a}+\mathrm{L} / /$ & $\mathrm{a}_{6}+\mathrm{L} / /$ & 2972.97 & 27 & 35.51 \\
\hline & $a+N / /$ & $\mathrm{a}_{6}+\mathrm{N} / /$ & 2979.63 & 27 & 42.17 \\
\hline & $\mathrm{a}+\mathrm{v} / /$ & $a_{6}+v / /$ & 2979.52 & 27 & 42.06 \\
\hline \multicolumn{6}{|c|}{ Models including multiple covariates } \\
\hline & $a+T+v / /$ & $\mathrm{T}+\mathrm{v} / /$ & 2975.71 & 28 & 40.26 \\
\hline & $\mathrm{a}+\mathrm{G}+\mathrm{T} / /$ & $\mathrm{G}+\mathrm{T} / /$ & 2954.70 & 28 & 19.25 \\
\hline & $a+G+F / /$ & $\mathrm{G}+\mathrm{F} / /$ & 2940.48 & 28 & 5.03 \\
\hline & $\mathrm{a}+\mathrm{F}+\mathrm{v} / /$ & $\mathrm{F}+\mathrm{v} / /$ & 2962.51 & 28 & 27.06 \\
\hline & $\mathrm{a}+\mathrm{T}+\mathrm{L} / /$ & $\mathrm{T}+\mathrm{L} / /$ & 2971.16 & 28 & 35.71 \\
\hline & $\mathrm{a}+\mathrm{G}+\mathrm{N}+\mathrm{G} \cdot \mathrm{N} / /$ & $\mathrm{G}+\mathrm{N}+\mathrm{G} \cdot \mathrm{N} / /$ & 2936.98 & 29 & 3.50 \\
\hline Model 18 & $\mathbf{a}+\mathbf{G}+\mathbf{L}+\mathbf{G} . \mathbf{L} / /$ & $\mathbf{G}+\mathbf{L}+\mathbf{G} . \mathbf{L} / /$ & 2934.16 & 29 & 0.71 \\
\hline Model 19 & $\mathbf{a}+\mathbf{G}+\mathbf{F}+\mathbf{G . F} / /$ & $\mathbf{G}+\mathbf{F}+\mathbf{G} . \mathbf{F} / /$ & 2933.44 & 29 & 0.00 \\
\hline
\end{tabular}

than the one explained by the per-capita food resources, despite the two variables were not independent. In contrast with what found for survival and recruitment the number of Audouin's gulls breeding in the area explained only $4.6 \%$ (Table 3 ).

\section{Discussion}

As expected, we found that population growth rate decreased with population density. Although this relationship has been commonly observed for a number of populations, the form of the dependence of population growth rate on population density has seldom been analysed (Turchin 1999). In our case such association was non-linear, more in accordance with other longlived birds (Sæther and Engen 2002). Furthermore the scatter of population values around the regression line (Fig. 1C) indicated that relative high levels of stochasticity also affected population growth rate (Sibly and Hone 2002).

We found that all demographic parameters except productivity were negatively associated with population density, but the strength of the relationship depended on the parameter considered, and when tested alone the population density explained about a third of the yearly variation of density. Contrary to expectations, we did not find evidence of an increase in the age of first breeding at high population densities or an association between density and productivity. We conclude that the observed dynamics resulted from the interplay of density-dependent and stochastic events, but a high turnover of individuals related to dispersal processes among local populations and the combined role of food availability in recruitment processes weaken densitydependent effects (Oro et al. 2006).

\section{Recruitment probability and age of first breeding}

About a third $(32 \%)$ of the year-to-year variability in recruitment probability was explained by Audouin's gull density. This relationship was mainly evident at the beginning of the study when recruitment probability decreased gradually during the period of exponential growth of the population (1992-1997; Fig. 3B). However, the average age of first breeding did not substantially change over the study period, although a negative feedback of population size was expected in 
long-lived species (Harris and Wanless 1991, Newton 1998, Eberhardt 2002). Pradel et al. (1997a) showed that recruitment of greater flamingos, Phoenicopterus ruber, increased after a massive adult mortality, and this suggests a density-dependent recruitment by interference competition (Tavecchia et al. 2001, Kokko et al. 2004). In our case, breeding habitat was not saturated and two recruitment pulses occurred in years of high population densities, in agreement with a stochastic temporal pattern in dispersal within the metapopulation (Oro and Ruxton 2001, Cam et al. 2004). However, recruitment seemed not dominated by stochastic process. When these two years were excluded from the regression, population size explained $70 \%$ of the remaining yearly variation in recruitment. Moreover, these recruitment pulses were partially explained by a linear combination of population size and food availability. Indeed, a model including Audouin's gull population, total fish catches at the local harbour and their interaction successfully reproduced most of the temporal variability in recruitment found here. Interestingly the absolute fish catches was a better predictor of recruitment than the average per-capita intake, although these variables were correlated.

\section{Survival and transience probabilities}

Among the covariables considered, we found that the total number of Audouin's was the best predictor of the temporal variability in survival of resident birds explaining nearly a third (34\%) of the total variance. Although the model was not retained, the proportion of variance explained by the population density is more than the average effect found in ecological studies (Møller and Jennions 2002). Similar negative correlations between population density and local adult survival were also recorded in other bird species (Frederiksen and Bregnballe 2000, Altwegg et al. 2003). In our case, in contrast with what found on recruitment, local survival decreased linearly over time even once population reached its equilibrium and the population size explained only $1 \%$ of the temporal variability around the trend. This suggested an important role of stochastic and catastrophic increases in mortality (e.g. the fox event) and emigration of established breeders, and in turn on dynamics at both local and metapopulation levels (Lande et al. 1999, Reed et al. 2003). Moreover, despite reaching an apparent equilibrium, an increasing proportion of gulls bred only once at the study colony, showing again the importance of spatial parameters in the regulation of open populations. Even after correcting for detection probability, an average of $7 \%$ of the population was estimated to be transitory. This suggests an increase in permanent emigration (and not in mortality, supported by the resights of these birds breeding in other populations, unpubl. data), for the newly seen gulls: we estimated that about 1400 individuals per breeding season breed only once at the colony. The presence of large number of transients was also recorded in other local populations of the species (Oro et al. 2004a). Such a large turnover of individuals per year confirms that dispersal, which is asymmetric between Audouin's gull populations (Cam et al. 2004) can be crucial for the dynamics (Oro and Ruxton 2001, Martínez-Abraín et al. 2003, Cam et al. 2004, Oro et al. 2004a). High proportions of transients are also common in invertebrate metapopulations and short-lived vertebrates (Perret et al. 2003), but its importance for the population dynamics of long-lived organisms has received less attention (Brooks and Lebreton 2001, Inchausti and Weimerskirch 2002). At an individual level, transient behaviour was more common among older gulls, which may reflect a lower quality phenotype of birds recruiting at older age and/or breeding only a few times in their life (Bradley et al. 2000). Alternatively, these animals may be regular breeders in other colonies and opportunistic breeders at the Ebro delta colony (PrevotJulliard 1996).

\section{Productivity}

The average productivity was the only parameter that increased even when population fluctuated around its equilibrium. This result was unexpected since several studies in colonial long-lived birds have shown that productivity declines when populations reach a critical density (Coulson et al. 1982, Hamer et al. 1991, Jehl 1994, Kilpi 1995). The average productivity of Audouin's gulls was associated with changes in total food availability (see similar results in Birkhead and Furness 1985, Cairns 1992) more than the per-capita amount of resources and more than survival and recruitment probabilities appeared to be. A possible explanation could be that density-dependence acted at the beginning of the breeding season and/or it was related to resources other than per capita food (Sæther and Engen 2002).

\section{Conclusions}

Importantly, we showed how none of the intrinsic or extrinsic factors affected demographic parameters equally. Population density had a general negative influence in local survival, transience and recruitment, but not in productivity. However, high values of recruitment were also observed at high population densities, due to a combination of density-dependent and -independent factors, which provide the potential for unexpected increases in the number of breeding pairs, probably generating a departure from the 
expected relationship of population density and population growth rate. The role of recruitment in our case mirrors the one of fertility in some long-lived mammals (Clutton-Brock and Coulson 2002). In fact, recruitment pulses at high population densities might have buffered a population decline predicted by the negative trend of survival. This was also due to the open feature of the study population and its connectivity with other populations and to the fact that breeding output was directly associated with food availability but not with population density. Finally, no covariate alone explained more than a third of the yearly variation in any demographic parameter. Our study shows that the strength of the negative feedback of population size depends on the parameter considered and that open population are equally influenced by stochastic events than by intrinsic factors. This is in agreement with recent analyses of long-term population counts that showed how the variation in the growth rate of bird populations is often largely affected by stochastic components (Sæther and Engen 2002).

Acknowledgements - The authors are much indebted to all the people who helped ringing more than 15000 chicks at the colony during the study. In particular Albert Bertolero made a great contribution to the field work. Xavier Ruiz, Lluis Jover, Sisco Vidal and Albert Martinez provided logistic and very helpful supervision. We are also grateful to the Ebro Delta Natural Park and its staff for their help with the ringing programme and permissions. Remi Choquet gave precious advices at an early step of the analysis. Jean-Michel Gaillard and Tim Benton gave very helpful comments on previous drafts of the manuscript. MG was founded by a I3P fellowship from the Spanish government (Ministerio de Educación y Ciencia). GT was founded by a post-doctoral grant from the Spanish government (Ministerio de Educación y Ciencia, ref. SB2002-0054). Funds were provided by grants from several agencies: Ministerio de Educación y Ciencia (ref. BOS2003-01960 and CGL2006-04325/BOS), ICONA, Generalitat de Catalunya and European Commission (ref. QLRT-2000-00839). Additional funds from the Biotechnology and Biological Sciences Research Council (ref. BBS/B/ 01219) were provided to GT during editing.

\section{References}

Altwegg, R. et al. 2003. Variation and covariation in survival, dispersal, and population size in barn owls Tyto alba. - J. Anim. Ecol. 72: 391-399.

Berryman, A. A. et al. 2002. Population regulation, emergent properties, and a requiem for density dependence. - Oikos 99: 600-606.

Birkhead, T. R. and Furness, R. W. 1985. The regulation of seabird populations. - In: Sibly, R. M. and Smith, R. H. (eds), Behavioural ecology. Blackwell, pp. 147-168.
Bradley, J. S. et al. 2000. Intermittent breeding in the shorttailed shearwater Puffinus tenuirostris. - J. Anim. Ecol. 69: 639-650.

Brooks, E. N. and Lebreton, J. D. 2001. Optimizing removals to control a metapopulation: application to the yellow legged herring gull. - Ecol. Modell. 136: 269-284.

Burnham, K. P. and Anderson, D. R. 2002. Model selection and inference. A practical information-theoretic approach. - Springer.

Cairns, D. K. 1992. Population regulation of seabirds colonies. - In: Power, D. M. (ed.), Current ornithology. Vol. 9, pp. 37-62.

Cam, E. et al. 2004. Assessment of hypotheses about dispersal in a long-lived seabird using multistate capture-recapture models. - J. Anim. Ecol. 73: 723-736.

Cappuccino, N. and Price, P. W. 1995. Population dynamics. New approaches and synthesis. - Academic Press.

Choquet, R. et al. 2000. U_Care: user's guide. ftp:// ftp.cefe.cnrs-mop.fr|publbiom $\backslash$ soft-CR2000.

Clobert, J. et al. 2001. Dispersal - Oxford Univ. Press.

Clutton-Brock, T. H. and Coulson, T. 2002. Comparative ungulate dynamics: the devil is in the detail. - In: Sibly, R. M. et al. (eds), Wildlife population growth rate. Cambridge Univ. Press.

Coulson, J. C. et al. 1982. Changes in the breeding biology of the herring gull (Larus argentatus) induced by reduction in the size and density of the colony. - J. Anim. Ecol. 51: 739-756.

Coulson, T. et al. 2001. Age, sex, density, winter weather and population crashes in Soay sheep. - Science 292: 15281531.

Crawley, M. J. 1993. GLIM for ecologists. - Blackwell.

Eberhardt, L. L. 1977. Optimal management policies for marine mammals. - Wildlife Soc. Bull. 5: 162-169.

Eberhardt, L. L. 2002. A paradigm for population analysis of long-lived vertebrates. - Ecology 83: 2841-2854.

Fowler, C. W. 1987. A review of density dependence in populations of large mammals. - In: Genoways, H. H. (ed.), Current mammalogy. Plenum Press, pp. 401-441.

Frederiksen, M. and Bregnballe, T. 2000. Evidence of density-dependent survival in adult cormorants from a combined analysis of recoveries and resightings. - J. Anim. Ecol. 69: 737-752.

Gaillard, J.-M. et al. 1998. Population dynamics of large herbivores: variable recruitment with constant adult survival. - Trends Ecol. Evol. 13: 58-63.

Grosbois, V. and Tavecchia, G. 2003. Modeling dispersal with capture-recapture data: disentangling decisions of leaving and settlement. - Ecology 84: 1225-1236.

Hamer, K. C. et al. 1991. The effects of changes in food availability on the breeding ecology of great skuas Catharacta skua. - J. Zool. (Lond.) 223: 175-188.

Hanski, I. and Gaggiotti, O. E. 2004. Ecology, genetics and evolution of metapopulations. - Academic Press.

Harris, M. P. et al. 2005. Effect of wintering area and climate on the survival of adult Atlantic puffins Fratercula arctica in the eastern Atlantic. - Mar. Ecol. Progr. Ser. 297: $283-296$.

Harris, M. P. and Wanless, S. 1991. Population studies and conservation of puffins Fratercula arctica. - In: Perrins, C. et al. (eds), Bird population studies, relevance to 
conservation and management. Oxford Univ. Press, pp. $231-248$.

Hixon, M. A. and Carr, M. H. 1997. Synergic predation, density dependence, and populaiton regulation in marine fish. - Science 277: 949-949.

Hixon, M. A. et al. 2002. Population regulation: historical context and contemporary challenges of open vs closed systems. - Ecology 83: 1490-1508.

Hurrell, J. W. 1995. Decadal trends in the North Atlantic oscillation and relationships to regional temperature and precipitation. - Science 269: 676-679.

Inchausti, P. and Weimerskirch, H. 2002. Dispersal and metapopulation dynamics of an oceanic seabird, the wandering albatross, and its consequences for its response to long-line fisheries. - J. Anim. Ecol. 71: 765-770.

Jehl, J. R. J. 1994. Absence of nest density effects in a growing colony of California gulls. - J. Avian Biol. 25: 224-230.

Kilpi, M. 1995. Further comments on nest density effects in large gulls. - J. Avian Biol. 26: 264-266.

Kokko, H. et al. 2004. Competition for breeding sites and site-dependent population regulation in a highly colonial seabird, the common guillemot Uria aalge. - J. Anim. Ecol. 73: 367-376.

Lande, R. et al. 1999. Spatial scale of population synchrony: environmental correlation versus dispersal and density regulation. - Am. Nat. 154: 271-281.

Lebreton, J.-D. and Clobert, J. 1991. Bird population dynamics, management, and conservation: the role of mathematical modelling. - In: Perrins, C. M. et al. (eds), Bird population studies, relevance to conservation and management. Oxford Univ. Press, pp. 105-125.

Lebreton, J. D. et al. 1992. Modeling survival and testing biological hypotheses using marked animals: a unified approach with case studies. - Ecol. Monogr. 62: 67-118.

Lloret, J. et al. 2001. Fluctuations of landings and environmental conditions in the north-western Mediterranean Sea. - Fish. Oceanogr. 10: 33-50.

Martínez-Abraín, A. et al. 2003. Modeling temporal and spatial colony-site dynamics in a long-lived seabird. - Popul. Ecol. 45: 133-139.

Matthysen, E. 2005. Density-dependent dispersal in birds and mammals. - Oecologia 28: 403-416.

Møller, A. P. and Jennions, M. P. 2002. How much variance can be explained by ecologists and evolutionary biologists? - Oecologia 132: 492-500.

Murdoch, W. W. 1994. Population regulation in theory and practice. - Ecology 75: 271-287.

Newton, I. 1998. Population limitations in birds. - Academic Press.

Oro, D. 1999. Trawler discards: a threat or a resource for opportunistic seabirds?. - In: Adams, N. J. and Slotow, R. H. (eds), Proc. 22 Int. Ornithol. Congr.-Johannesburg: BirdLife South Africa, pp. 717-730.

Oro, D. and Pradel, R. 1999. Recruitment of Audouin's gull to the Ebro Delta colony at metapopulation level in the western Mediterranean. - Mar. Ecol. Progr. Ser. 180: $267-273$.

Oro, D. and Ruxton, G. D. 2001. The formation and growth of seabird colonies: Audouin's gull as a case study. - J. Anim. Ecol. 70: 527-535.
Oro, D. et al. 1999. Food availability and nest predation influence life history traits in Audouin's gull, Larus audouinii. - Oecologia 118: 438-445.

Oro, D. et al. 2004a. Modelling demography and extinction risk in the endangered Balearic shearwater. - Biol. Conserv. 116: 93-102.

Oro, D. et al. 2004b. Influence of food availability on demography and local population dynamics in a longlived seabird. - Proc. R. Soc. Lond. B 271: 387-396.

Oro, D. et al. 2006. Influence of density-dependence on predator-prey seabird interactions at large spatio-temporal scales. - Proc. R. Soc. Lond. B 273: 379-383.

Perret, N. et al. 2003. Transience, dispersal and survival rates in newt patchy populations. - J. Anim. Ecol. 72: 567575.

Pfister, C. A. 1998. Patterns of variance in stage-structured populations: evolutionary predictions and ecological implications. - Proc. Nat. Acad. Sci. USA 95: 213-218.

Pollock, K. H. et al. 1990. Statistical inference for capturerecapture experiments. - Wildlife Monogr. 107.

Pradel, R. and Lebreton, J.-D. 1999. Comparison of different approaches to the study of local recruitment of breeders. Bird Study 46: 74-81.

Pradel, R. et al. 1997a. Capture-recapture survival models taking account of transients. - Biometrics 53: 60-72.

Pradel, R. et al. 1997b. Local recruitment in the greater flamingo: a new approach using capture-mark-recapture data. - Ecology 78: 1431-1445.

Prevot-Julliard, A.-C. 1996. Role de la dispersion dans la dynamique d'une population de mouette rieuse Larus ridibundus. - Univ. de Montpellier II, France.

Pulliam, H. R. 1988. Sources, sinks, and population regulation. - Am. Nat. 132: 652-661.

Reed, D. H. et al. 2003. The frequency and severity of catastrophic die-offs in vertebrates. - Anim. Conserv. 6: $109-114$.

Rodo, X. et al. 1997. Variations in seasonal rainfall in southern Europe during the present century: relationships with the North Atlantic oscillation and the El Niñosouthern oscillation. - Climate Dynamics 13: 275-284.

Sæther, B.-E. and Engen, S. 2002. Pattern of variation in avian population growth rates. - Philos. Trans. R. Soc. Lond. B 357: 1185-1195.

Schwarz, C. J. and Arnason, A. N. 2000. Estimation of agespecific breeding probabilities from capture-recapture data. - Biometrics 56: 59-64.

Sibly, R. M. and Hone, J. 2002. Population growth rate and its determinants: an overview. - Philos. Trans. R. Soc. Lond. Ser. B 357: 1153-1170.

Sinclair, A. R. E. 1996. Mammal populations: fluctuation, regulation, life history theory and their implications for conservation. - In: Floyd, R. B. et al. (eds), Frontiers of population ecology. CSIRO Publishing.

Stenseth, N. C. and Lima, M. 2002. Ecological effects of climate fluctuations. - Science 297: 1292-1296.

Tavecchia, G. et al. 2001. Sex- and age-related variation in survival probability and the cost of the first reproduction in breeding greater flamingos. - Ecology 82: 165-174.

Tavecchia, G. et al. 2005. Predictors of reproductive cost in female Soay sheep. - J. Anim. Ecol. 74: 201-213. 
Turchin, P. 1995. Population regulation: old arguments and a new synthesis. - In: Cappuccino, N. and Price, P. V. (eds), Population dynamics: new approaches and synthesis. Academic Press.

Turchin, P. 1999. Population regulation: a synthetic view. - Oikos 84: 153-159.

Turchin, P. 2001. Does population ecology have general laws? - Oikos 94: 17-26.
Weimerskirch, H. 2002. Seabird demography and its relationship with the marine environment. - In: Schreiber, E. A. and Burger, J. (eds), Biology of marine birds. CRC press, pp. 115-135.

White, G. C. and Burnham, K. P. 1999. Program MARK: survival estimation from populations of marked animals. - Bird Study 46 (suppl.): 120-129.

Williams, B. K. et al. 2002. Analysis and management of animal populations. - Academic Press. 